\title{
Heparitin Sulfate Mucopolysaccharidosis (Sanfilippo Disease): A Case Study with Ultrastructural, Biochemical, and Radiological Findings
}

\author{
M. Daria Haust ${ }^{[53]}$, Bruce A. Gordon ${ }^{[54]}$, Alex M. Bryans, D. G. Wollin, and Vera Binnington \\ The Departments of Pathology, Pediatrics, and Radiology, Kingston General Hospital and Queen's University, Kingston; Departments of \\ Pathology and Biochemistry, The Children's Psychiatric Research Institute and University of Western Ontario, London; \\ and Ontario Hospital School, Orillia, Ontario, Canada
}

\begin{abstract}
Extract
A case study of a 14-year-old female child who developed normally for 18 months but subsequently deteriorated rapidly in mental status and social behavior is reported. Histochemical studies of tissues removed at biopsy from liver, skin, and bone marrow showed changes similar to those found in the Hurler syndrome. Ultrastructural changes of the liver were also similar to those found in the above syndrome with the exception of the presence of mitochondrial crystalloids not observed to date in the Hurler disease. Heparitin sulfate constituted the bulk of the acid mucopolysaccharides in the urine with only traces of chondroitin sulfate B present. In view of these observations and the lack of clinical and radiological findings generally associated with the Hunter and Hurler syndromes the diagnosis of Sanfilippo disease was made.
\end{abstract}

\section{Speculation}

On the basis of the finding that the pattern of acid mucopolysaccharide (AMPS) excreted in urine in our patient differed from that of 12 other children with Sanfilippo disease [12], it is speculated that two subtypes of this disease exist characterized by different patterns of excretion of the AMPS in urine. Whether this difference will prove to be extended to other manifestations is not known at present, but it is conceivable that the difference in radiological findings (in our case minimal and nonspecific, in other cases resembling those of the Hurler and Hunter syndromes), degree of mental retardation, or morphological features, may parallel these biochemical differences. It would be important, therefore, to study other children with Sanfilippo disease in detail, to determine whether other variables are consistent with varying patterns of excretion of AMPS in urine.

\section{Introduction}

Brante [3] suggested in 1952 that Hurler disease is not a form of lipochondrodystrophy but rather a mucopolysaccharidosis. Subsequently, it became apparent on the basis of intensive clinical, pathological, and bio- chemical studies that there are several distinct variants of this disease. These have been grouped together with similar diseases with aberrations in metabolism of acid mucopolysaccharides (AMPS) as the genetic mucopolysaccharidoses. Langer [21] and Maroteaux and Lamy [27] suggested the group comprised 
five diseases. It is questionable whether the ill defined Scheie disease is a separate entity as suggested by some $[30,38]$. On the other hand, a localized form of acid mucopolysaccharidosis affecting only the eye [11] could logically be added as a sixth member to this series.

The disease first described as a distinct clinical and biochemical entity by Sanfilippo and his associates [37] belongs to the above group. Paper chromatographic analyses of AMPS excreted in large quantities in the urine of two of their patients with some of the clinical features of the Hunter and/or Hurler syndromes, disclosed only heparitin sulfate present in excess [37]. Children with the classic Hunter or Hurler syndromes are known to excrete in addition chondroitin sulfate B [8, 31]. Meyer et al. [31], Lorincz [25], and Harris [14] in earlier work had reported that heparitin sulfate alone was responsible for the excessive AMPS excreted by some children. In addition to certain somatic features characteristic of either the Hunter or Hurler syndrome, and heparitin sulfaturia, children suffering from this disease were characterized by severe mental retardation. Subsequent to the description by Sanfilippo et al. [37] other cases have been reported by several authors $[1,7,13,22,26-29,41,43]$, and the literature has been reviewed [34].

In the differential diagnosis of the mucopolysaccharidoses the characterization of AMPS in urine has recently received increased attention. Although it has been inferred that heparitin sulfate is the only AMPS excreted in excess in the Sanfilippo disease, chondroitin sulfate $B$ may also be excreted in small quantities by some of these patients [35].

The presently reported findings in a 14-year-old female child with this disease, who has been followed for 7 years, illustrate the above point; it is emphasized that a correct diagnosis of any of the genetic mucopolysaccharidoses may be established only on the basis of combined clinical, radiological, biochemical, and pathological observations. Moreover, it is probable that children with Sanfilippo disease do not constitute a homogeneous group.

\section{Case Report}

\section{Clinical Data}

This 14-year-old, white female patient was born at term in July, 1954; she was the third of five children of healthy, intelligent, young, and unrelated parents. The pregnancy, labor, delivery, and neonatal period were normal and the baby weighed at birth $3.4 \mathrm{~kg}$.
She gained weight satisfactorily, walked at 14 months, and was toilet-trained at approximately 2 years. In year 2, the patient developed a copious nasal discharge, and the parents were concerned about the slowness in learning to speak and the possibility of partial deafness. At 18 months the patient was capable of saying a few words, but she never progressed to forming sentences. In 3 rd and 4 th years of life she exhibited progressive deterioration and became hyperactive and difficult to manage. She would harm the younger siblings, eat any available object (cigarette butts, soil, etc.) and when displeased, would shriek and whine. A shortened attention span, destructability and withdrawal became increasingly apparent. She lost her clean bowel habits, and by 5 years of age, the parents were convinced of her mental retardation. This was confirmed by medical examination and psychological testing.

At 6.5 years (February, 1961) the patient was admitted to the Ontario Hospital School in Orillia where she was described as a dull, apathetic child, tall for her age, measuring $122 \mathrm{~cm}$ in height (75th percentile) and weighing $27.3 \mathrm{~kg}$ (85th percentile). She had lost her ability to speak and uttered only incoherent sounds, but she still retained the ability to walk. Her facial features were coarse with thick-set heavy eyebrows, flat nasal bridge, heavy jaws, thick lips and tongue, and a large scaphocephalic skull. The skin was dry and coarse. She was described as slender but had a moderately protuberant abdomen. The liver and spleen appeared somewhat enlarged. The vision and eyes were normal. At the time of admission her mental age was estimated to be at the level of 18 months, with an IQ of 23; electroencephalogram (EEG) was normal; serum level of cholesterol was $125 \mathrm{mg} / 100 \mathrm{ml}$, of calcium 9.0 $\mathrm{mg} / 100 \mathrm{ml}$, of phosphorus $3.6 \mathrm{mg} / 100 \mathrm{ml}$, alkaline phosphatase 9.5 Bodansky units, and protein-bound iodine was $5.9 \mu \mathrm{g} / 100 \mathrm{ml}$. In the cerebrospinal fluid the chlorides were $708 \mathrm{mg} / 100 \mathrm{ml}$, protein $40 \mathrm{mg} /$ $100 \mathrm{ml}$, colloidal gold was 1121100000 , and no cells were present. She was afforded custodial and nursing care.

When the patient came to the attention of the authors, a urinary spot test showed that the patient ex. creted large amounts of AMPS. Since, however, her external appearance was not typical of that seen in patients with Hurler's syndrome, the patient was admitted in October 1961 for investigation at the age of 7 years to the Kingston General Hospital (KGH) [44]. She showed obvious severe mental retardation. There was a mild thoracolumbar kyphosis when the patient was in the sitting position, but it disappeared when she 


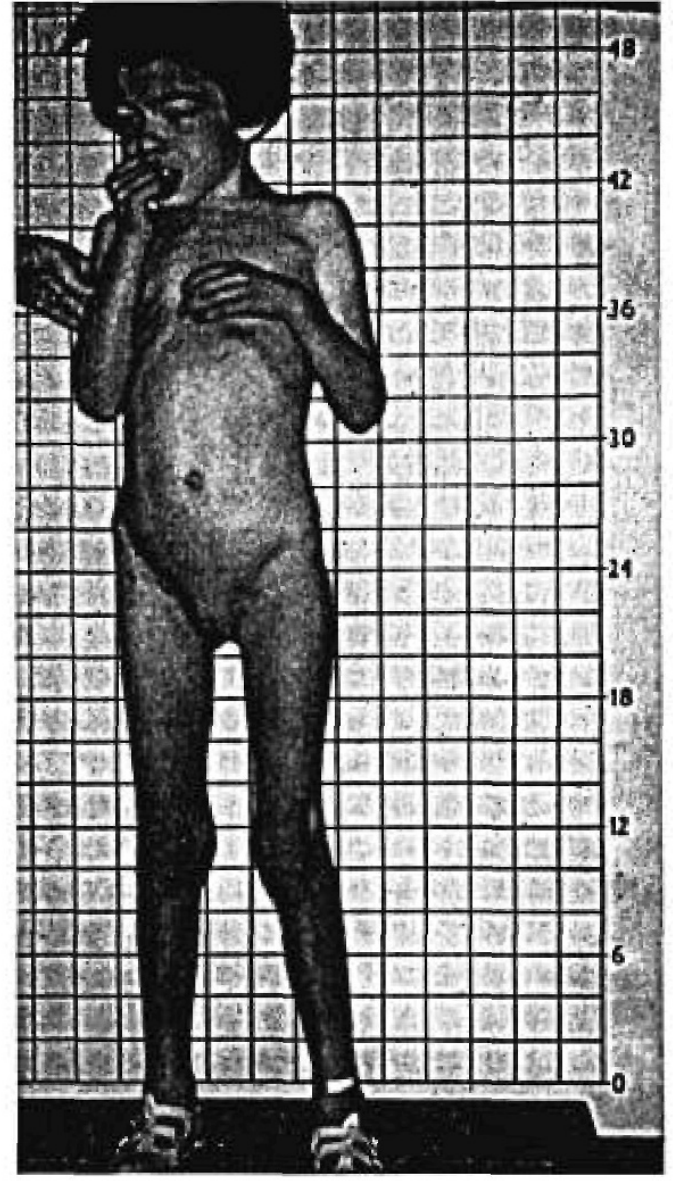

Fig. 1. External appearance of the patient at the age of 7 years (first admission to KGH).

was standing (Fig. l). She measured $121 \mathrm{~cm}$ in height and weighed $21 \mathrm{~kg}$. The facial features were those observed on hospital admission to Orillia. The liver and spleen were not appreciably enlarged. The fingers and toes were cold, and slightly clubbed and cyanosed. Detailed hearing testing could not be carried out, but the patient reacted to loud sounds. Studies of urine and formed elements in blood were normal. Serum proteins were $7.6 \mathrm{~g} / 100 \mathrm{ml}$ with normal electrophoretic pattern. The EEG showed grossly abnormal, continuous, generalized, low voltage dysrhythmia, with little or no background activity. Cells from bone marrow, and white cells from peripheral blood showed the presence of typical intracytoplasmic inclusions; these were often situated in a vacuole. Biopsy specimens were obtained under general anesthesia from skin, liver, bone marrow, and rectal mucosa for histochemical, histological, and electron microscopic examination.

The child was readmitted in December, 1965, at age
11 years to. $\mathrm{KGH}$. for further assessment. There had been further deterioration in her mental status. Her facial features were much coarser than they had been on her first admission to KGH in 1961 and she had developed some restriction of extension at the elbows and knees. The clubbing of her fingers and toes was more accentuated but not extreme. Urinalysis showed $2+$ albumin, numerous red blood cells (RBCs) and 8-10 WBCs per high power field, urine culture yielded 1,300,000 Candida albicans $/ \mathrm{ml}$ and the urinary spot test was again positive for metachromasia; hemoglobin and white blood count were normal; numerous, large, intracytoplasmic metachromatic inclusions, often present in vacuoles, were again observed in the peripheral leukocytes. Chromatograms of urine showed generalized aminoaciduria. By means of an indwelling catheter, urine was collected over three separate 24-hr periods and subjected to analyses for AMPS.

\section{Radiological Studics}

Ossification corresponded to the chronological age of the patient; changes in the skeleton were not very prominent. The vault of the skull was thickened, had a coarse trabccular structure (Fig. 2), and suture lines were still prominent. It was otherwise normal as was the vertebral column. The mineral content of the bones

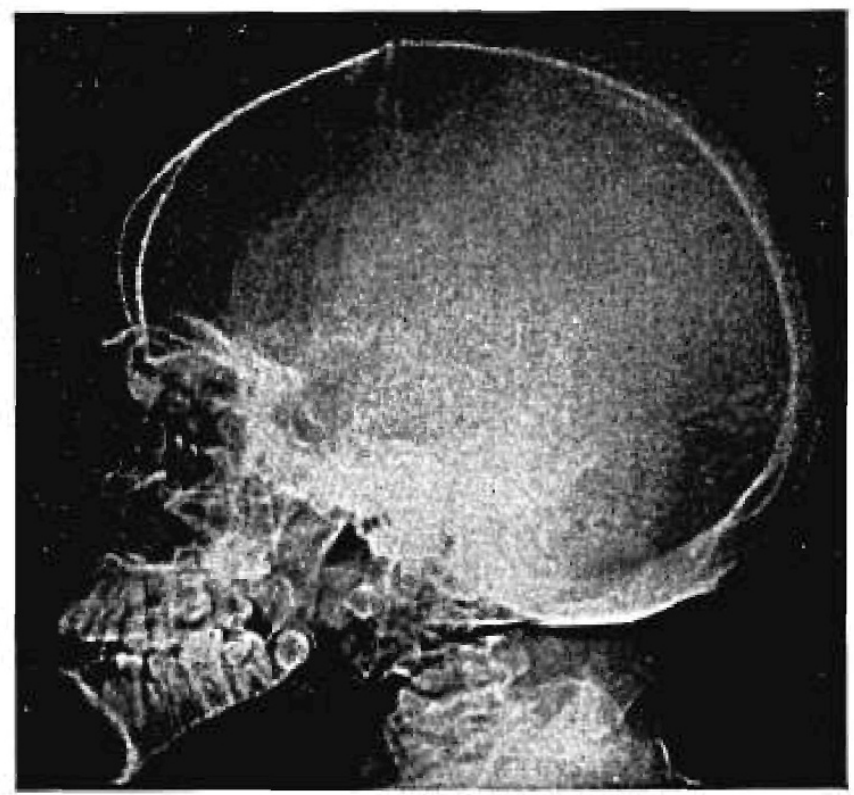

Fig. 2. X-ray of skull, lateral view: the vault is thick with gencrally coarse trabeculation; the sutures are patent and the pituitary fossa is normal. 


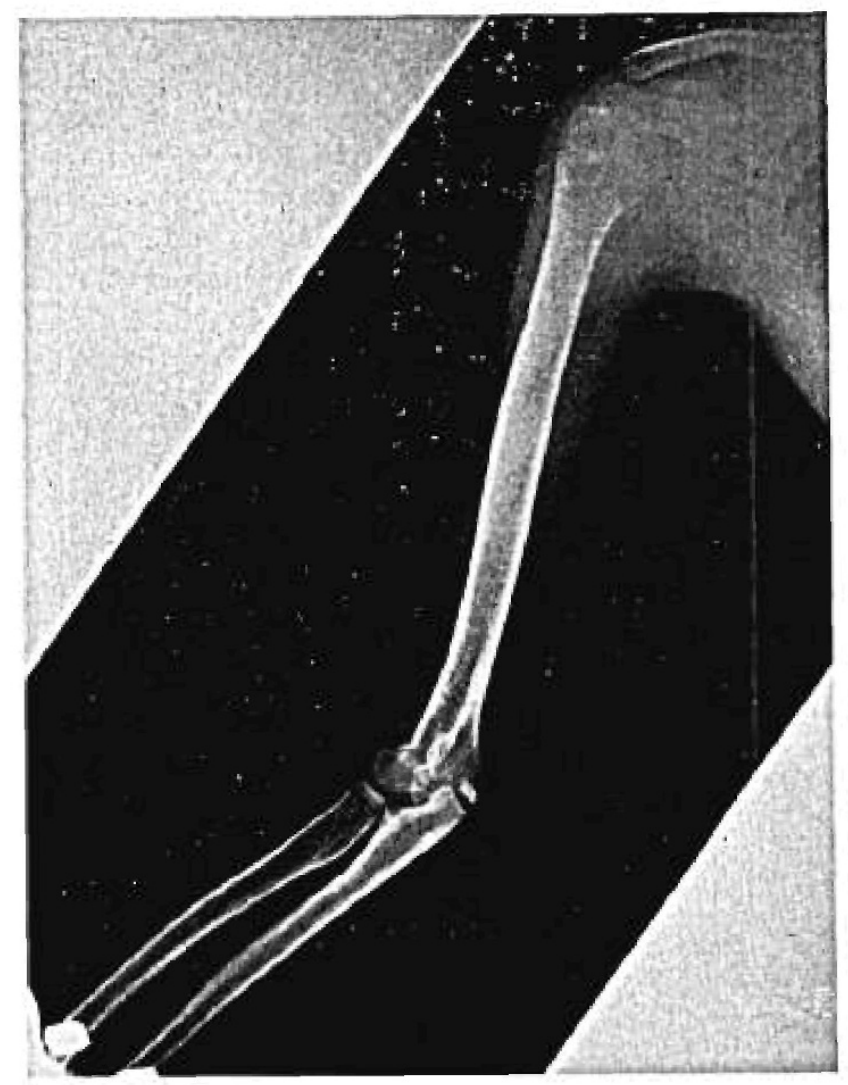

Fig. 3. Upper extremity; anteroposterior view shows minimal expansion of the proximal end of the radius (lack of complete modeling).

was diminished; there was coarse trabeculation in the flat bones, and thinned cortices with minimal expansion of the shaft and lack of complete modeling of the long bones. This incomplete modeling was minor in degree and most readily perceptible in the proximal end of the radius (Fig. 3). In addition, there was lack of ossification and presumably of development of the contiguous aspects of the distal radial and ulnar epiphyses so that these presented a deeper bony cavity for the carpus than normally present. No other skeletal changes were observed. No additional changes were detected on radiological examination on the second admission of the patient to KGH.

\section{Biochemical Studies}

Urine collected over a 24-hr period was pooled, frozen, and stored until analyzed. The AMPS in the urine were isolated by the method of Di Ferrante and Rich [5]. An aliquot of the AMPS mixture $(15 \mathrm{mg})$ was chromatographed on a $1 \mathrm{~cm}$ by $45 \mathrm{~cm}$ column of Dowex $1 \times 2$ (100-200 mesh, Cl- form) [45] according to the method of Schiller et al. [39] eluting with increasing concentrations of $\mathrm{NaCl}$. Fractions of $5.0 \mathrm{ml}$ were collected, and orcinol [4] and carbazole [6] reactions were carried out on each. Fractions within each peak were pooled, dialyzed against distilled water, and reduced to dryness under vacuum. The residue was subjected to paper chromatography [40] and electrophoresis on cellulose acetate strips [26], and the mobility of individual AMPS was compared with those of authentic standards. Reference standards consisted of chondroitin sulfate A [46]; chondroitin sulfate B, isolated from pig skin as outlined by Jeanloz [20]; chondroitin sulfate $\mathbf{C}$ [47]; and heparitin sulfate [48]. The latter was chromatographed on a column [39, 45], and that appearing in the $1.25 \mathrm{M}$ saline eluate was utilized as our heparitin sulfate standard. For the purpose of establishing the amino sugar components and thus facilitating the identity of the specific AMPS, the AMPS were hydrolyzed and separated from other carbohydrates on a Dowex 50 column [49] as described by Boas [2]. The hexosamine mixture was chromatographed on paper [50] in normal butanol-pyridine-water $(5: 3: 2, v / v)$ against standards of D-glucosamine and D-galactosamine hydrochlorides. Another aliquot $(15 \mathrm{mg}$ ) of the mucopolysaccharide mixture was dissolved in $1.5 \mathrm{ml}$ of 0.1 $M$ acetate buffer and digested with testicular hyaluronidase as outlined by Linker and Terry [23]. Following dialysis of the hydrolysate the residue was chromatographed on an anion exchange resin column [45], and the desalted fractions were analyzed as outlined above.

The total AMPS output in urine during three 24-hr periods was 54, 62, and $88 \mathrm{mg}$, respectively. The elution pattern of the mixed AMPS from urine chromatographed on a column is shown in Figure 4a, and that following digestion with testicular hyaluronidase is depicted in Figure $4 b$. In the mixture of AMPS four components were apparent. The ratio of their reactivity with carbazole and orcinol provided some indication of their identity. Under similar experimental conditions, the carbazole to orcinol ratio for heparitin sulfate is approximately 2.5 ; chondroitin sulfates $\mathrm{A}$ and $C, 2.0$; and chondroitin sulfate $B, 0.5$. The material eluted with 1.0 and $1.25 \mathrm{M} \mathrm{NaCl}$ was apparently unaffected by the testicular hyaluronidase; however, most of that eluted with 1.5 and $2.0 \mathrm{M} \mathrm{NaCl}$ was eliminated from the mixture. Chondroitin sulfates $\mathrm{A}$ and $\mathrm{C}$, the major AMPS of normal urine [23] (which should be eluted from the column with 1.5 and $2.0 \mathrm{M} \mathrm{NaCl}$ ) are digestible with testicular hyaluronidase whereas chondroitin sulfate $B$ is affected to only a limited extent by this enzyme [10] and heparitin sulfate is not digested.

On paper chromatographs the AMPS mixture from urine was not resolved into well delineated spots. A 


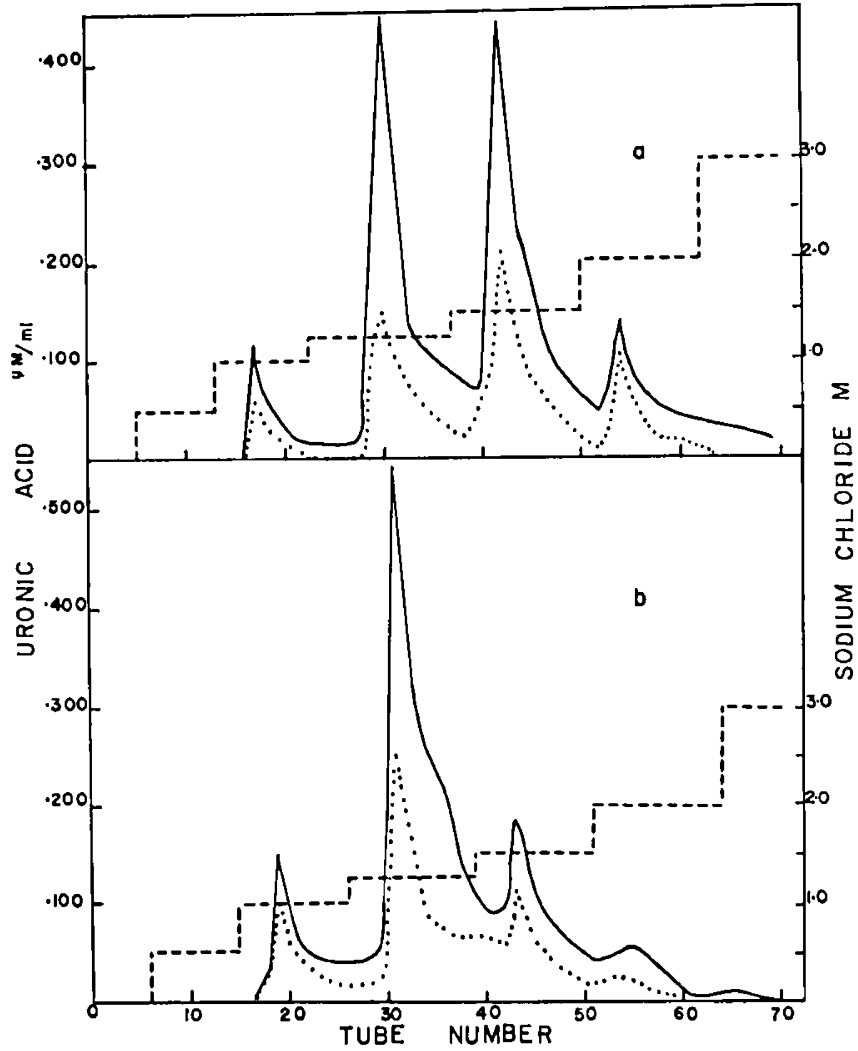

Fig. 4. Elution diagram of urinary acid mucopolysaccharides on a column [45] before $(a)$ and after $(b)$ digestion with testicular hyaluronidase. - Carbazole reaction. $\cdots$ : Orcinol reaction. ---: Sodium chloride concentration.

diffuse streak was produced which extended from the level of the heparitin sulfate to the chondroitin sulfate A standard. Material eluted with 1.0 м $\mathrm{NaCl}$ ran just with the tail of the heparitin sulfate standard, while that eluted with $1.25 \mathrm{M} \mathrm{NaCl}$ paralleled this standard (Fig. 5a). These compounds were not altered by the digestion with testicular hyaluronidase (Fig. $5 b)$. The bulk of AMPS eluted with 1.5 and $2.0 \mathrm{~m} \mathrm{NaCl}$ ran with a chondroitin sulfate A standard (Fig. $5 a$ ), and these components were eliminated by hydrolysis with testicular hyaluronidase (Fig. $5 b$ ) leaving only substances responsible for the tailing of the undigested fractions.

Densitometric tracings of cellulose acetate electrophoretograms of the fractions from the column [45] are shown in Figure 6. Material in the 1.0 and $1.25 \mathrm{M}$ eluate was slightly less mobile than the heparitin sulfate standard, while that in the 1.5 and $2.0 \mathrm{M}$ fractions had a mobility similar to that of chondroitin sulfate standards. Following testicular hyaluronidase digestion the 1.0 and $1.25 \mathrm{M}$ eluates were unchanged; however, the fractions eluted with 1.5 and $2.0 \mathrm{M} \mathrm{NaCl}$ were now electrophoretically similar to the material in the 1.25 i NaCl eluate. The identity of amino sugars released on hydrolysis of the fractions from the Dowex-1 columns [45] are shown in Table I. The glucosamine present in eluant fractions is the amino sugar of heparitin sulfate, and the galactosamine in the 1.5 and $2.0 \mathrm{M}$ eluate is from chondroitin sulfate. Persistence of a galactosaminoglycan after testicular hyaluronidase digestion indicates the presence among the AMPS excreted by the patient of a small quantity of chondroitin sulfate $B$ although the bulk of the material excreted was heparitin sulfate.

\section{Morphological Studies}

Tissues obtained at biopsy from skin, bone marrow, and liver were utilized in the present study. For paraflin embedding, a portion of tissue was fixed in neutral $10 \%$ formalin. For demonstration of the presence of AMPS, the tissues were frozen and subse-

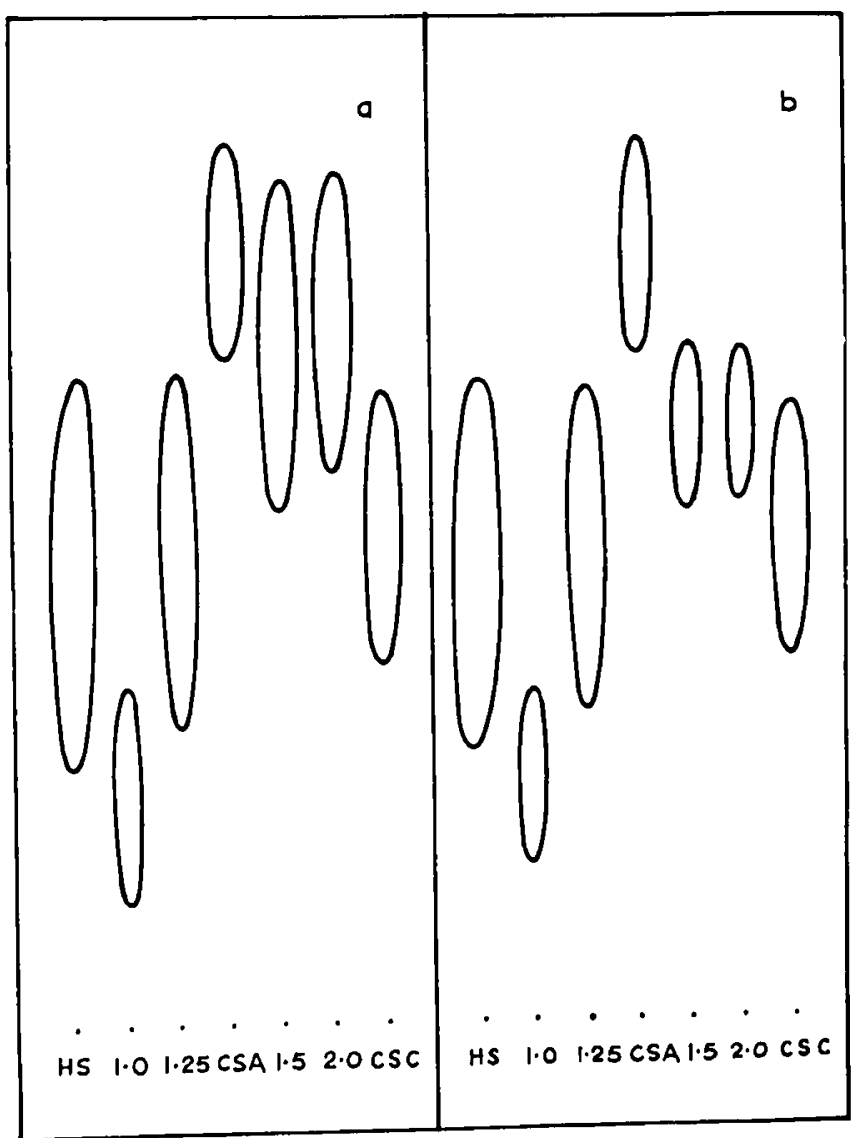

Fig. 5. Paper chromatograms of fractions from column chromatography of acid mucopolysaccharides in urine before $(a)$ and after $(b)$ digestion with testicular hyaluronidase. HS: Heparitin sulfatc. CSA: Chondroitin sulfate $A$. CSC: Chondroitin sulfate C. 


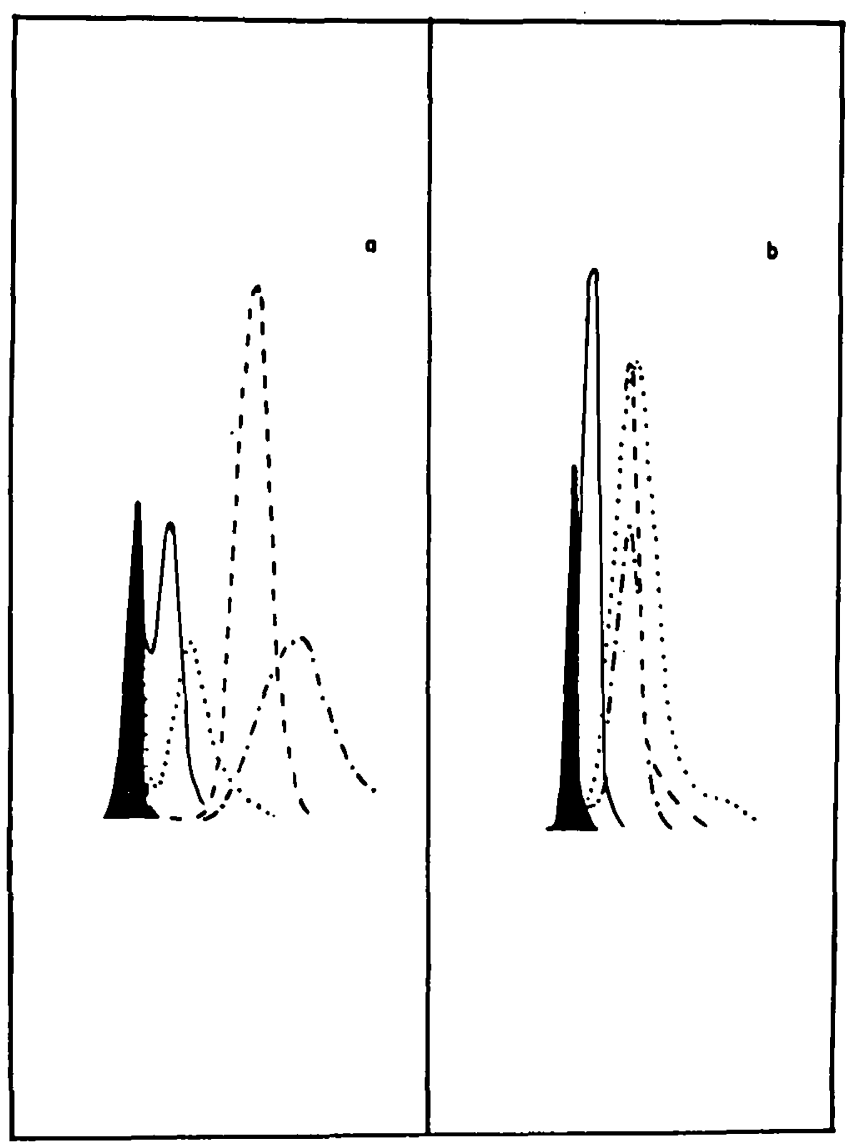

Fig. 6. Densitometric tracings of fractions from column chromatography of acid mucopolysaccharides in urine bcfore $(a)$ and after $(b)$ digestion with testicular hyaluronidase. Solid peak: Hyaluronic acid used as a reference. - - : $1.00 \mathrm{M} \mathrm{NaCl}$ eluate. $\cdots: 1.25 \mathrm{M} \mathrm{NaCl}$ eluate. $--: 1.50 \mathrm{M} \mathrm{NaCl}$ cluate. $--: 2.00 \mathrm{M}$ $\mathrm{NaCl}$ eluate.

quently processed as described elsewhere [18]. A portion of liver tissue was processed and examined with the electron microscope by methods detailed elsewhere $[15,16,19,36]$.

No changes were observed in sections of skin from paraffin-embedded tissue. With the special procedure on frozen tissue sections stained with toluidine blue (pH 2), however, intense metachromasia was apparent in the extracellular space of the skin, especially accentuated between the collagen bundles. In addition, metachromatic granules were present in the cells of dermal papillae and in some cells in the depth of the corium. In paraffin-embedded sections of the aspirated bone marrow, cells with large, somewhat hollow granules were occasionally observed; these granules stained with metachromatic stains and alcian blue (both indicating the presence of AMPS). The granules were present in cells presumably belonging to the myelocytic series. Reference to these features was made previously [17]. In paraffin-embedded tissues, liver parenchymal cells appeared grossly distorted and vacuolated. No material could be demonstrated in these vacuoles with either metachromatic or fat stains. With the special technique the liver appeared "solid" in sections (Fig. 7) owing to the presence of an intensely metachromatic, homogeneous, and slightly granular substance which filled not only the sinusoids but also the hepatocytes. This metachromatic substance was not present in the control tissue which had been processed identically (Fig. 8).

One-micron-thick section from plastic-embedded material revealed under the electron microscope the presence of numerous vacuoles in the liver parenchyma, distended sinuosoids, and distorted architecture (Fig. 9). These features were similar to those observed in paraffin-embedded tissues; in addition, smaller vacuoles were present in Kupffer cells. On closer inspection, not all vacuoles appeared empty. An ill defined floccular or reticular, faintly stained material was observed in many of these vacuoles. Another feature observed in these preparations was the presence of some bizarrely shaped or giant mitochondria (Fig. 9).

Electron micrographs revealed that the parenchymal liver cells were in various stages of degeneration and regeneration. The picture was dominated by the presence of numerous round to oval vacuoles, which were of different sizes and contained materials of various nature (Fig. 10). This intravacuolar material was usually finely floccular and moderately electron-dense (Fig. 10), but in addition, numerous small round and homogeneous bodies (Fig. 11) or membranous arrays, as well as small fibrils (Fig. 12), were observed. Moreover, some vacuoles contained distinct electron-dense

Table I. Hexosamine relcased on hydrolysis of acid mucopolysaccharides

\begin{tabular}{ccc}
\hline Eluate fraction $^{1}$ & Glucosamine & Galactosamine \\
\hline \multirow{2}{*}{1.0} & $4+$ & \\
& $(4+)^{2}$ & \\
1.25 & $4+$ & \\
& $(4+)$ & $3+$ \\
1.5 & $1+$ & $(1+)$ \\
& $(3+)$ & $4+$ \\
2.0 & tr & $(2+)$ \\
& $(2+)$ & \\
\hline
\end{tabular}

${ }^{1}$ Molarity of $\mathrm{NaCl}$ solution used for clution.

2 Data in parentheses refer to acid mucopolysaccharides sub. jected to testicular hyaluronidase. 


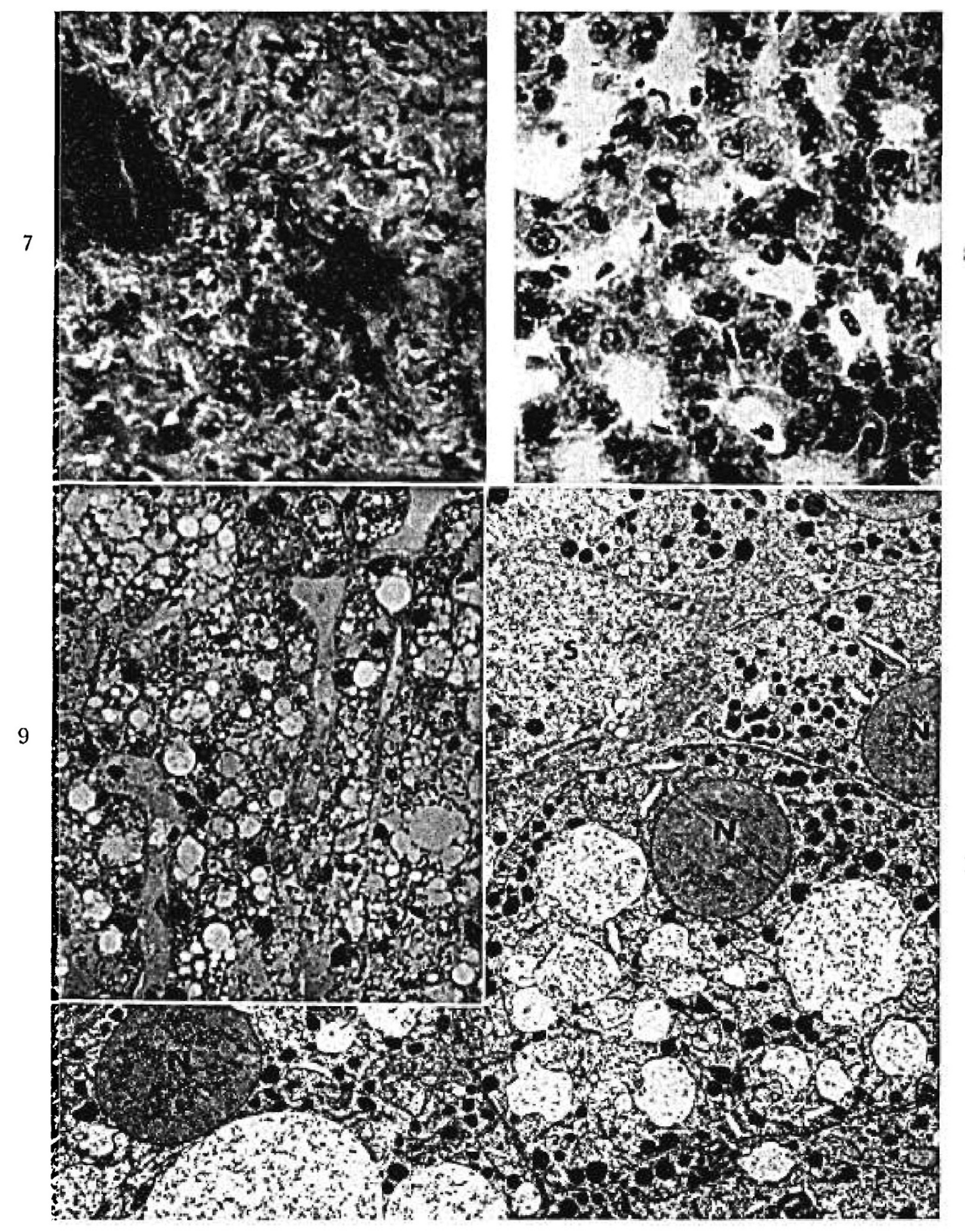

8

Fig. 7. Liver tissue obtained at biopsy, processed by a special technique [18], and stained with toluidine blue (pH 2). The liver tissue as such is recognizable with difficulty. Two dilated sinusoids contain dark, finely granular, and homogeneous material (dark grey in photograph, strongly metachromatic on section); similar material is seen intermingled with the hepatocytes. $\times 480$.

Fig. 8. Control liver tissue processed identically to that illustrated in Figure 7. Normal liver architecture is apparent, and no metachromatic substance is present either in the sinusoids or within the liver cells. $\times 480$.

Fig. 9. One-micron-thick section cut from liver tissue prepared for electron microscopy and embedded in plastic. It is difficult to recognize the tissue as liver parenchyma. Numerous intracytoplasmic vacuoles of various sizes and content are present in liver cells. Some of the vacuoles appear empty; others are filled with finely stainable material and thus impart upon the vacuole a slightly grey color. Mitochondria appear as tiny, numerous dark dots; however, a few, huge, elongated, or round mitochondria are also visible in this section. Kupffer and endothelial cells contain only small vacuoles. $\times 387$.

Fig. 10. Low power electronmicrograph of hepatocytes. The picture is dominated by the presence of numerous vacuoles in the cytoplasm of the cells. They contain various amounts of finely granular material. Confluence of these vacuoles and rupture of the limiting membrane produce areas of disintegration in some cells. Other cells contain only few of these vacuoles. Material similar to that present in the vacuoles is also observed in the dilated sinusoid (S) which in addition contains cellular debris and frecly floating mitochondria. Note that the nuclei (N) do not contain nucleoli. $\times 2,800$. 


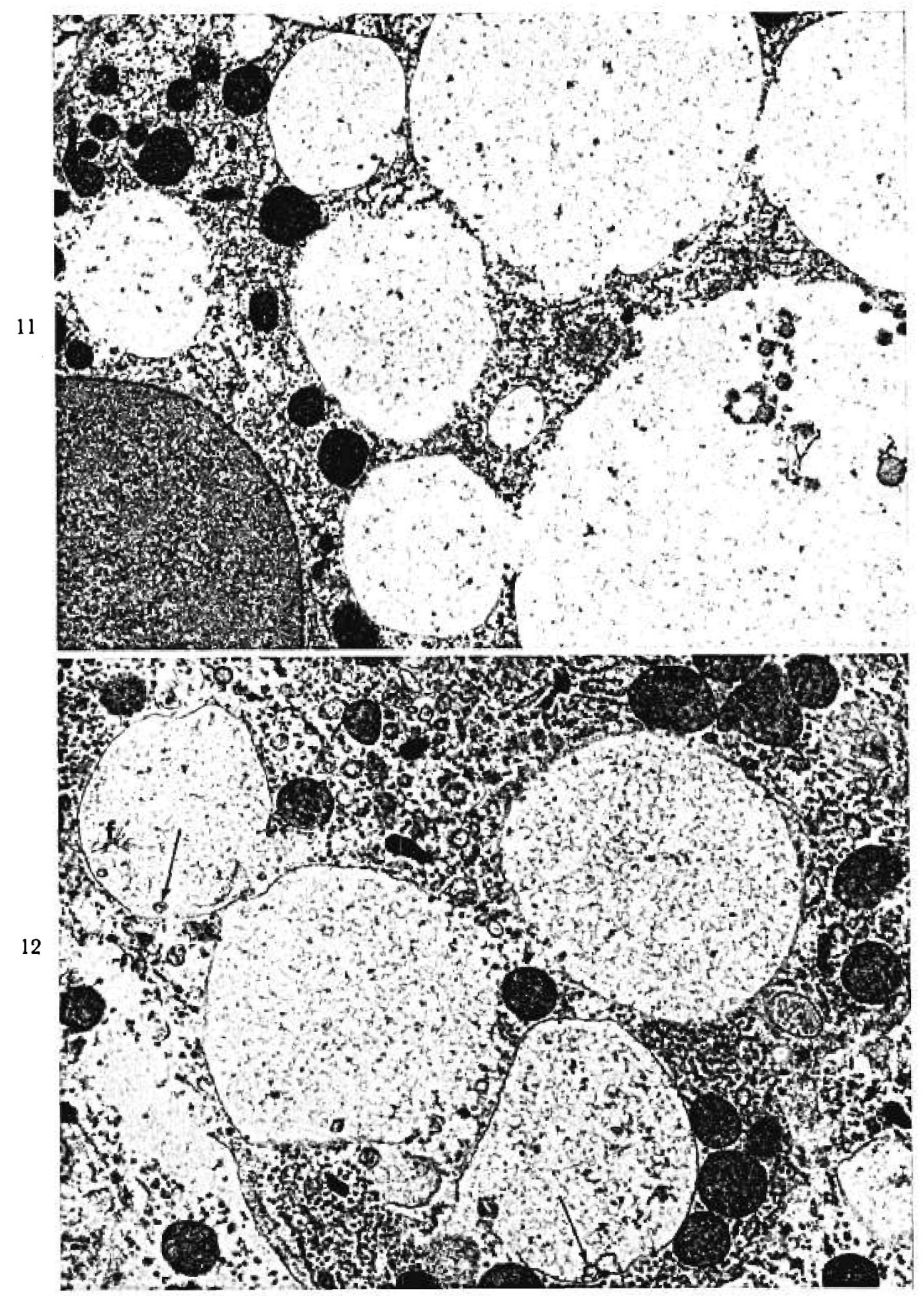

Fig. 11. Intracytoplasmic vacuoles are entirely membrane-bound when they are small (cenler). The larger vacuoles are only partially membrane-bound, fuse with one another, and in many areas merge with the hyaloplasm. A moderate amount of finely granular or floccular material is present in vacuoles; in addition, one contains small, round, homogencous, moderately clectrondense, and usually membrane-bound bodies. In the nucleus (left lower half of photograph) coarse granules are interspersed with a rather uniform nuclcoplasm; no nucleolus is present. $\times 6,300$.
Fig. 12. In addition to the finely floccular and granular material present in the cytoplasmic vacuoles, there are a few membranous (arrow), and vesicular profiles, and long fibrils (f) present. Note that mitochondria vary not only in shape, but in size and electron density. There are numerous tiny vesicles interspersed through. out the cytoplasm. The rough-surfaced endoplasmic reticulum is relatively well preserved. $\times 9,900$. 


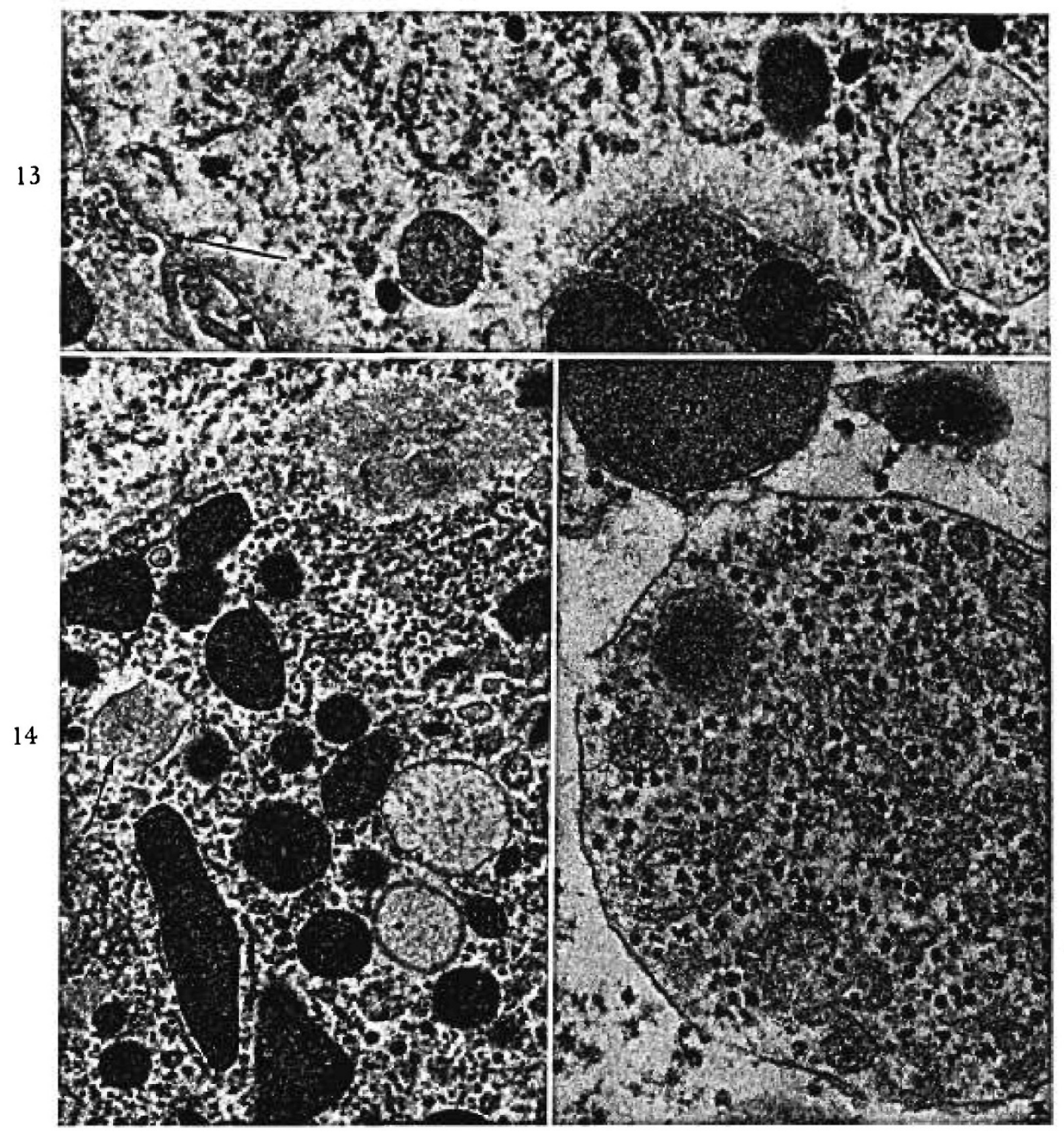

Fig. 13. Glycogen particles are present in the intracytoplasmic vacuole along with finely floccular material (extreme right of photograph). There is a paucity of endoplasmic reticulum, particularly on the right. A rim of finely filamentous intracytoplasmic material is seen along the plasma membrane (arrow). $\Lambda$ few narrow profiles of endoplasmic reticulum are "curled-up" and some fused end-to-end. Numerous, round, electron-dense bodies, considerably smaller than the mitochondria are present in the cytoplasm; some of these are reminiscent of peribiliary bodies. A few small vesicles are scattered throughout the cytoplasm. Mitochondria, glycogen granules, and finely fibrillar material are present in dilated intercellular space (left lower corner). $\times 12,6000$.

Fig. 14. A pool of finely filamentous material is seen in one cytoplasmic area (upper right half), and similar material can be observed in one partially membrane-bound area (arrow). Two small membrane-bound vacuoles contain material similar to that observed in Figures 10-13. Mitochondria vary in size, shape, and electron density. $\times 9,300$.

Fig. 15. An autophagic vacuole contains several intracytoplasmic components and appears to be attached partially to a mitochondrion (m). $\times 32,500$.

granules morphologically similar to glycogen particles (Fig. 13). At times, material which was neither floccular nor granular but finely filamentous was observed in the hyaloplasm either as a pool or partially membranebound (Fig. 14). Similar, finely filamentous material was also observed as a rim at the plasma membrane (Fig. 13). Occasionally, autophagic vacuoles containing various cytoplasmic organelles were present in the cytoplasm (Figs. 13 and 15).

Mitochondria, which varied considerably in shape 


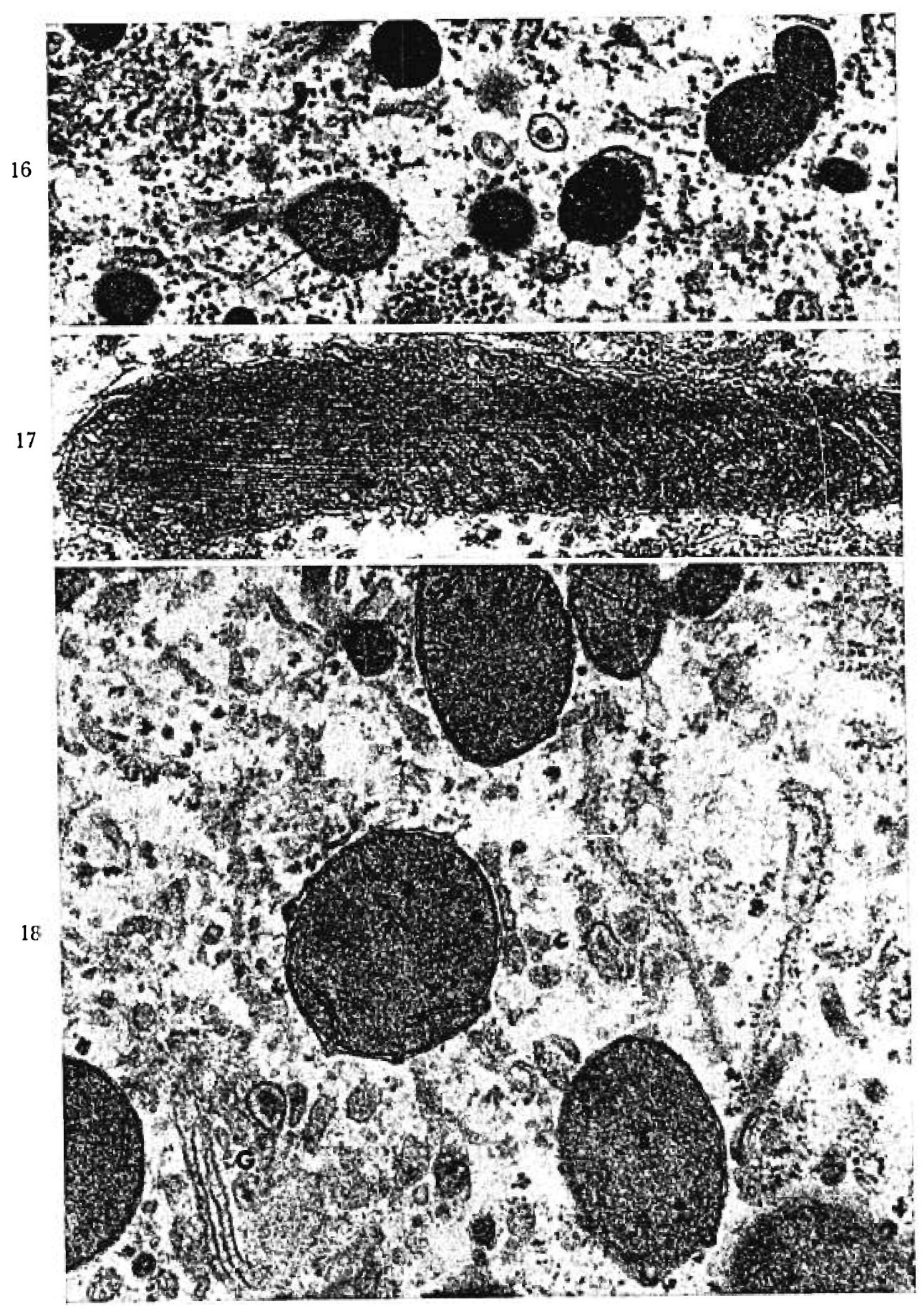

Fig. 16. Mitochondria vary in size, shape, and elcctron density. One mitochondrion is in division (at right of photograph). Glycogen granules are present in what appears to be an altered mitochondrion (arrow). Other structures, reminiscent of mitochondria but having some features of dense bodics, are also observed in the cytoplasm. $\times 19,500$.

Fig. 17. A large mitochondrion of a hepatocyte contains in its matrix parallel filaments disposed in a longitudinal arrangement typical of an intramitochondrial crystalloid. $\times 50,200$.

Fig. 18. A prominent Golgi zone $(G)$ with some dilated and electron-dense material containing vesicles; well preserved mitochondria displaying the phenomenon of "budding" [16], and a moderate number of profiles of rough-surfaced endoplasmic reticulum are observed in a regenerating hepatocyte. $\times 41,300$. 
and size (Fig. 14), were observed in division (Fig. 16) and contained occasionally crystalloids (Fig. 17) [15]. Another unusual feature of the mitochondria was "budding." The buds originated from the inner mitochondrial membrane (Fig. 18) and were, often but not always, associated with cristae. Glycogen was present at times in structures reminiscent of mitochondria by shape and electron density (Fig. 16). The nucleus had a loose texture, and in sections examined no nucleolus was observed (Figs. 10 and 11).

The cellular preservation varied considerably from area to area. Frank disintegration of cells was associated with the "release" into the hyaloplasm of the floccular or fibrillar material from large vacuoles (Fig. 10). Eviclence of regeneration was also apparent. The degree of cellular integrity was indicated by the presence or absence of various cytoplasmic organelles. The endoplasmic reticulum was well preserved only in regenerating cells and in cells with relatively few or no vacuoles (Figs. 12 and 14), but even here, it was often degranulated, of unusual shape, and had a tendency to circular arrangement (Fig. 13). In well preserved and in regenerating cells the Golgi apparatus was prominent (Fig. 18). Numerous tiny vacuoles limited by either a single or double membrane were observed in the cytoplasm of all cells, whether they be regenerating or degenerating. In addition, dense bodies, smaller than mitochondria, were also observed in the cytoplasm (Figs. 13, 14, and 16). These were not necessarily associated with the peribiliary area of the hepatocytes. The hepatic sinusoids and intercellular spaces and recesses were often extremely dilated and filled with cytoplasmic components derived from degenerating hepatocytes; mitochondria, glycogen granules, and finely filamentous material were identifiable among these (Fig. 13). The sinusoidal endothelial and Kupffer cells contained only small vacuoles with finely filamentous material.

\section{Discussion}

Prior to 1962-1963 [37] children with the Sanfilippo disease (S. disease) either were considered to have a form fruste of the Hurler or Hunter syndromes (17), or were not distinguished at all from these syndromes. It is probable that numerous cases of $S$. disease were never reported as either of the above. It would be misleading, therefore, to assume that this is an extremely rare disease, as could be incorrectly deduced from the rather small number of cases reported. $[1,7,9,21,22$, $27-30,35,37,41,43]$. In the most recent report Rampini collected 49 cases from the literature and added 8 of his own [34]. It is understandable that initially children suffering from $S$. disease were assumed to belong to either the Hunter or the Hurler group, as some signs and symptoms are common to all three diseases (mental retardation, coarse facial features with thick lips, heavy eyebrows, low set hair line, large tongue, and enlargement of liver and spleen) and all excrete large quantities of AMPS. Occasionally they may share impairment or loss of hearing. Whereas originally the children with $S$. disease were described as being tall and slender, and lacking the osseous changes characteristic of the two other mucopolysaccharidoses, newly accumulating data suggest that stocky build and radiological appearance of the ribs indistinguishable from that present in the Hurler and Hunter syndromes may be present in some children with S. disease [12].

The disease under discussion was separated from the other mucopoiysaccharidoses on the basis of biochemical analysis of substances excreted in urine. Whereas patients with the Hurler and Hunter syndromes excrete both chondroitin sulfate $B$ and heparitin sulfate, the urine of children who were thought to have a different physical appearance (see above) were reported initially to contain only heparitin sulfate [37]. The latter substance has been implicated in the pathogenesis of mental retardation considered to be much more severe in $S$. disease than that in the two other syndromes. It would be most advantageous if this separation on a biochemical basis were as clear-cut as it appeared at first. However, small quantities of a hyaluronidase-resistant galactosaminoglycan, presumably chondroitin sulfate $B$, have been found in the AMPS in the urine of our patient, a child who lacks most of the physical stigmata of the Hurler and Hunter syndromes, but with clinical features compatible with S. disease. This material was not separated from the heparitin sulfate of the same column fractions by either paper chromatography or electrophoresis on cellulose acetate. Small amounts of chondroitin sulfate $B$ in the urine of children with S. disease was observed previously [35] but may have been overlooked in most of the reported studies, especially in those using paper chromatography [41] owing to the proximity of this fraction to heparitin sulfate. The presence of small quantities of chondroitin sulfate $B$ in the present case probably reflects differences in methods employed, as small quantities of this AMPS were also observed in our other patients with the same disease [12], and in patients in another study [35]. It may be also mentioned that the pattern of AMPS excretion in the presently reported patient differed in other ways from the 
remaining patients studied by us [12]. It is conceivable that among patients with Sanfilippo disease there are subtle but definite differences which may justify subgrouping. Details regarding these differences and the implications of these finclings are discussed elsewhere [12].

Two questions come to mind in view of the above mentioned findings: (1) should the Sanfilippo disease be redefined, and, if so, what criteria should be utilized in validating this diagnosis; (2) is it correct to separate this entity only on a biochemical basis before the basic metabolic error has been defined? The excreted AMPS do not reflect those accumulated in the various tissues [32], and, moreover, tissue AMPS in S. disease are reported to be similar to those found in the Hurler and Hunter syndromes [43]. The accumulating and excreted AMPS may not have arisen as a direct consequence of the basic error but could be related to it only circuitously. If these questions are tenable, then we must be able, at least until such time when the basic defect can be determined, to characterize and recognize this disease perhaps on the basis of additional criteria. In search of the latter it would appear logical to turn to tissue changes accompanying the disease. But the apparent preoccupation with the biochemistry of the $S$. disease provided little stimulus for pathological studies as attested by only a few reports on morphology in this disease $[9,13,15,16,43]$.

In the present studies, tissues processed by a method previously devised to preserve the very soluble AMIPS of Hurler disease showed the presence of a strongly metachromatic substance in the hepatic cells and sinusoids, and in the dermis between collagen bundles and in cells. In its staining quality, precise site of accumulation, and degree of solubility in aqueous solutions, this substance resembled that found in the liver and skin of patients with Hurler disease [18]. Moreover, the results of bone marrow examination were also similar in both groups; it has been well documented by others that metachromatic inclusions in the white blood cells are present in both Sanfilippo and Hurler disease [30]. Our electron microscopic studies of the liver showed in the cytoplasm of hepatocytes the presence of vesicles and vacuoles varying in number and size. These cytoplasmic structures contained a fincly granular or filamentous substance interpreted as AMPS. This interpretation was based on the observation that when hepatic tissues were processed by conventional methods resulting in the loss of metachromatic substances (AMPS), numerous empty vacuoles remained in the cytoplasm of hepatocytes. In addition, a few membranous arrays and glycogen granules were observed in these vacuoles by electron microscopy. Similar results of ultrastructural studies of liver in children with $S$. disease have been reported by two groups of investigators $[13,43]$; it was concluded on the basis of staining for acid phosphatase that these vacuoles were lysosomal in nature [49]. The above features are indistinguishable from those observed in livers of children with Hurler syndrome [19, 24, 33], and it is not surprising that the results of a study of hepatic ultrastructure in a child later considered to have S. disease was originally included in a series of children with Hurler syndrome [13, 42]. It would therefore appear that one cannot distinguish the two diseases on the basis of examination of skin, white blood cells, and liver with perhaps one exception. Mitochondrial crystalloids and huge, bizarrely shaped mitochondria were found in the hepatic cells of children with S. disease (Fig. 17) [15], whereas they have not been observed in the liver of children with Hurler syndrome [19, 33]. A much larger number of cases in either group, however, will have to be studied before the above observation could be generalized and becomes a valid criterion for distinguishing the two clisease groups. It is of interest to Iearn that neuronal changes observed in the brains of patients with these two conditions appear identical [9].

In view of the present state of knowledge it appears justified to classify our patient as having the Sanfilippo disease. The patient did not have the build, osseous changes, corneal opacitics, or umbilical hernia characteristic of either Hurler or Hunter syndrome. Moreover, the natural history in this case was somewhat different from that of the two syndromes; i.e., the child developed normally until the age of 18 months when mental status and social behavior deteriorated. Whereas the tissues examined resembled those of the two other mucopolysaccharidoses, a feature not reported to date in the latter was observed in our patient, i.e., mitochondrial crystalloids in hepatocytes [15]. The bulk of the AMPS in urine consisted of heparitin sulfate. In addition, the patient excreted small quantities of chondroitin sulfate $B$, which is characteristic of both the Hurler and Hunter syndromes, but has not been encountered in the $S$. disease by others. Clarification of this and other problems raised above must await further work.

\section{References and Notes}

1. Bergełrd, I., and Bearn, $A$. G.: The Hurler syndrome. Amer. J. Med., 39: 221 (1965). 
2. Boss, N. F.: Method for the determination of hexosamines in tissues. J. Biol. Chem., 204: 553 (1953).

3. Brante, G.: Gargoylism-A mucopolysaccharidosis. Scand. J. Clin. Lab. Invest., f: 43 (1952).

4. Brown, A. H.: Determination of pentose in the presence of large quantities of glucose. Arch. Biochem., 11: 269 (1946).

5. Di Ferrante, N., and Rich, C.: The mucopolysaccharide of normal human urine. Clin. Chim. Acta, 1: 519 (1956).

6. Dische, Z.: A new specific color reaction of hexuronic acids. J. Biol. Chem., 167: 189 (1947).

7. Dorfman, A.: Heritable diseases of connective tissues: The Hurler syndrome. In: J. B. Stanbury, J. B. Wyngaarden, and 1). S. Frederickson: The Metabolic Basis of Inherited Discase, p. 963 (McGraw Hill, New York, 1966).

8. Dorfman, A., AND Lorincz, A. E.: Occurrence of urinary acid mucopolysaccharides in Hurler syndrome. Proc. Nat. Acad Sci. U.S.A., 13: 443 (1957).

9. Escourolle, R., Berger, B., ANI Polrier, J.: Biopsic cérébrale d'un case de mucopolysaccharidose II. S. (oligophrénic polydystrophique ou maladie de Sanfilippo) étude histochimique. et ultrastructuralle. Presse Med., 7t: 2869 (1966).

10. Fransson, L.-A., AND Roden, L.: Structure of dermatan sulfate. I. Degradation by testicular hyaluronidase. J. Biol. Chem., 2ł2: 4161 (1967).

11. Goldberg, M. F., Maumenef, A. E., and McKusick, V. A.: Corneal dystrophics associated with abnormalitics of mucopolysaccharide metabolism. Arch. Ophthalmol., 7t: 516 (1965).

12. Gokdon, B. A., ANd Haust, M. D.: The mucopolysaccharidoses types I, II and III: Urinary findings in 23 cases. Clin. Biochem., 3: 203 (1970).

13. Grenet, P., Lestradet, H., Dugas, M., Sarkut, S., Banoual, J., AND Alinert, L.: Mucopolysaccharidose avec élimination d'héparitine-sulfate (oligophrénic polydystrophi(jue). Presse Med., 74 : 2863 (1966).

14. Harkis, R. C.: Mucopolysaccharide disorder: A possible new genotype of Hurler's syndrome. Amer. J. Dis. Child., 102: 741 (1961).

15. HAust, M. D.: Crystalloid structures of hepatic mitochondria in children with heparitin sulphate mucopolysaccharidosis (Sanfilippo typc). Exp. Mol. Pathol., 8: 123 (1968).

16. Haust, M. D.: Mitochondrial budding and morphogenesis of cytoplasmic vacuoles in hepatocytes of children with the Hurler syndrome and Sanfilippo disease. Exp. Mol. Pathol., 9: 242 (1968).

17. Haust, M. D., Bryans, A. M., AND Frank, H. F.: Children with Hurler's syndrome institutionalized in Ontario's Provincial facilities. Recent Advan. Biol. Psychiat., 5: 93 (1963).

18. Haust, M. D., ANd Landing, B. H.: Histochemical studies in Hurler's disease: A new method for localization of acid mucopolysaccharide and an analysis of lead acetate "fixation." J. Histochem. Cytochem., 9: 79 (1961).

19. Haust, M. D., Orizaga, M., Bryans, A. M., ani Frank, 11. C.: The fine structure of liver in children with Hurler's syndrome. Exp. Mol. Pathol., 10: 141 (1969).

20. Jeanioz, R. W.: Dermatan sulfate. In: R. L. Whistler: Methods in Carbohydrate Chemistry, Vol. V, General Polysaccharides, p. 114 (Academic Press, New York, 1965).

21. LANGER, L. O.: The radiographic manifestations of the HSmucopolysaccharidosis of Sanfilippo with discussion on this condition in relation to the other mucopolysaccharidoses and a classification of these fundamentally similar entitics. Ann. Radiol., 7: 315 (1964).

22. Leroy, J. G., ANn Crocker, A. C.: Clinical definition of the Hurler-Hunter phenotypes. Amer. J. Dis. Child., 112: 518 (1966).

23. LINker, A., AND Terry, K. D.: Urinary acid mucopolysaccharides in normal man and in Hurler's syndrome. Proc. Soc. Exp. Biol. Med., 113: 743 (1963).

24. Lof., H., Jonniaux, G., Resimois, A., Cremer, N., Donion, J., Tondeur, M., Gregoire, P. E., Richarakd, J., and Cieters, P.: Biochemical and ultrastructural studies in Hurler's syndrome. J. Pediat., 73: 860 (1968).

25. LoRINCz, A. E.: Acid mucopolysaccharides in the Hurler syndrome. Fed. Proc., 17: 266 (1958).

26. Manley, G., and Hawksworth, J.: Diagnosis of Hurler's syndrome in the hospital laboratory and the determination of its genetic type. Arch. Dis. Child., 41: 91 (1966).

27. Maroteaux, P., ANil Lamy, M.: L'oligophrénie polydystrophique (Mucopolysaccharidose II.-S.). Presse Med., 72: 2991 (1964).

28. Maroteaux, P., ani Lamy, M.: Hurler's discase, Morquio's disease, and related mucopolysaccharidoses. J. Pediat., 67: $312(1965)$.

29. Mayes, J. S., and Hansen, R. G.: Mucopolysaccharide excretion in patients with Hurler's syndrome, their families, and normal man. Proc. Soc. Exp. Biol. Med., 122: 927 (1966).

30. Mickusick, V. A., Kaplan, D., Wise, D., Hanley, W. B., Sumbarth, S. B., Sfyick, M. E., and Maumanee, A. E.: The genetic mucopolysaccharidoses. Medicine, ft: 445 (1965).

31. Meyer, K., Grumibach, M. M., Linkfr, A., and Hoffman, P.: Excretion of sulfated mucopolysaccharides in gargoylism (Hurler's syndrome). Proc. Soc. Exp. Biol. Med., 97: 27.5 (1958).

32. Meyer, K., Hoffaian, P., Linker, A., and GrumbaCi, M. M.: Sulfated mucopolysaccharides of urine and organs in gargoylism (Hurler syndrome). II. Additional studies. Proc. Soc. Exp. Biol. Med., 102: 587 (1959).

33. Orizaga, M., Haust, M. D., Bryans, A. M., and Frank, H. F.: Electron microscopic study of liver in Hurler's syndrome. Fed. Proc., 22: 484 (1963).

34. Ramini, S.: Das Sanfilippo-Syndrom (polydystrophe Oligophrénic, HS-M Iukopolysaccharidose). Bericht über 8 Fälle und Literaturübersicht. Helv. Paediat. Acta, $1: 55$ (1969).

35. Rennfrt, O. M., and Dekaban, A. S.: Modification of urinary mucopolysaccharide excretion in paticnts with Hurler's syndrome. Clin. Pharmacol. Ther., 7: 783 (1966).

36. Rosen, D. A., Haust, M. D., Yanashita, T., and Bryans, A. $M$.: Keratoplasty and electron microscopy of the cornca in systemic mucopolysaccharidosis (Hurler's disease). Can. J. Ophthalmol., 3: 218 (1968).

37. Sanfilippo, S. J., Podosin, R., Lancier, L., and Goon, R. A.: Mental retardation associated with acid mucopolysacchariduria (heparitin sulfate type). J. Pediat., 63: 837 (1963).

38. Schfie, H. G., Hambrick, G. W., JR., and Barnes, L. A.: A newly recognized form fruste of llurler's disease (gargoylism). Amer. J. Ophthalmol., 53: 753 (1962).

39. Schit.l.er, S., Stover, G. A., AND Dorfman, A.: A method for the separation of acid mucopolysaccharides. Its application to the isolation of heparin from the skin of rats. J. Biol. Chem., 236: 983 (1961).

40. SPOlter, L., AND Marx, W.: Paper chromatography of 
heparin and related sulfated mucopolysaccharides. Biochim. Biophys. Acta, 38: 123 (1960).

41. TrkRY, K., AND LiNkER, A.: Distinction among four forms of Hurler's syndrome. Proc. Soc. Exp. Biol. Med., 115: 394 (1964).

42. VAN Hoof, F., AND Hers, H. G.: L'ultrastructure des cellules hépatique dans la maladie de Hürler (Gargoylisme). C. R. Acad. Sci. (Paris), 259: 1281 (1964).

43. Wallace, B. J., Kaplan, D., Adachi, M., Schineck, L., and Votk, B. W.: Mucopolysaccharidosis type III. Morphologic and biochemical studies of two siblings with Sanfilippo syndrome. Arch. Pathol., 82: 462 (1966).

44. Informed consent was obtained in accordance with the pro. visions of the Declaration of Helsinki. Permission was received to release photograph of patient.

45. Dowex $1 \times 2$, J. T. Baker Chemical Company, Phillipsburg N.J.

46. Nutritional Biochemicals Co., Cleveland, O.
47. Kindly furnished by Dr. K. Meyer, Yeshiva Univ., New York, N. Y.

48. A gift of the Upjohn Co. of Canada, Toronto, Ont.

49. Dowex $\mathrm{W} \times \mathrm{Z}, \mathrm{J}$. T. Baker Chemical Company.

50. Whatman 1, H. Reeve Angel, Inc., Clifton, N.J.

51. The authors thank Mrs. Carolyn Martin, Miss Charlotte Turnbull, and Mrs. Janice Conway for their skillful technical assistance, and Mrs. Phyllis Cloghesy for efficient typing of the manuscript.

52. Supported by Ontario Mental Health Foundation Grant no. 214 and Medical Research Council of Canada Grants nos. MT-1037 and MA-2326.

53. Requests for reprints should be addressed to: M. Daria Haust, M.D. Department of Pathology, University of Western Ontario, London, Ontario, Canada.

54. Dr. Bruce A. Gordon is a Scholar of the Ontario Mental Health Foundation.

55. Accepted for publication May 22, 1970. 